\title{
Factors Associated with Persistence with Teriparatide Therapy: Results from the DANCE Observational Study
}

\author{
Deborah T. Gold, ${ }^{1}$ David L. Weinstein, ${ }^{2}$ Gerhardt Pohl, ${ }^{3}$ Kelly D. Krohn, ${ }^{3}$ \\ Yi Chen, ${ }^{3}$ and Eric S. Meadows ${ }^{3}$ \\ ${ }^{1}$ Departments of Psychiatry and Behavioral Sciences, Sociology, and Psychology and Neuroscience, \\ Duke University Medical Center, Durham, NC 27710, USA \\ ${ }^{2}$ Washington University School of Medicine, St. Louis, MO 63110, USA \\ ${ }^{3}$ Lilly Research Laboratories, Eli Lilly and Company, Indianapolis, IN 46285, USA
}

Correspondence should be addressed to Eric S. Meadows, emeadows@lilly.com

Received 4 April 2011; Accepted 23 June 2011

Academic Editor: David L. Kendler

Copyright ( $\odot 2011$ Deborah T. Gold et al. This is an open access article distributed under the Creative Commons Attribution License, which permits unrestricted use, distribution, and reproduction in any medium, provided the original work is properly cited.

Purpose. Determine patient-reported reasons for discontinuation with teriparatide. Methods. Patients taking teriparatide in a multicenter, prospective, and observational study were given three questionnaires: baseline, follow-up questionnaire 1 (QF1, 2 to 6 months), and follow-up questionnaire 2 (QF2, 12 months). Discontinuation reported at QF1 and QF2 was defined as "early" and "late," respectively, and remaining patients were considered persistent. Cochran-Armitage trend test was used to identify factors associated with discontinuation. Results. Side effects, concern about improper use, injection difficulties, and several patient-perceived physician issues were associated with early discontinuation. Low patient-perceived importance of continuing treatment, side effects, difficulty paying, and low patient-perceived physician knowledge were associated with late discontinuation. The most common specific reasons selected for discontinuing treatment were "concerns about treatment outweighing the benefits" $(n=53)$ and "difficulty paying" $(n=47)$. Conclusions. Persistence with teriparatide is dependent on managing side effects, addressing financial challenges, proper training, and obtaining support from the healthcare provider.

\section{Introduction}

Osteoporosis underlies 1.5 million fractures per year in the United States and imposes a tremendous financial and personal burden. It is characterized by low bone mass, deterioration of bone tissue, and disruption of bony architecture [1], and though it can be identified and successfully treated before fractures occur, adherence and persistence with therapy are made difficult by the need for long-term treatment, the frequently asymptomatic nature of the disease, and the fact that most patients taking treatment do not perceive a clinical benefit $[2,3]$. Only $16 \%$ to $50 \%$ of patients persist with therapy 12 months after initiation [4-8], for patients receiving any of the following: bisphosphonate, calcitonin, hormone replacement therapy (HRT), or selective estrogen receptor modulator (SERM).
Poor persistence and adherence to osteoporosis therapy have many adverse outcomes, including higher risk of fracture [9-11].

Multiple therapies are currently available for osteoporosis, but teriparatide (Forteo) is the only anabolic treatment [12]. It is administered by the patient as a once-daily subcutaneous injection $(20 \mu \mathrm{g})$ for up to 24 months [12]. The parenteral route of administration and higher cost of teriparatide as compared to bisphosphonates might hinder persistence with treatment. In addition, decreases in persistence with teriparatide may represent a costly healthcare expenditure with less than full protection against osteoporotic fracture, and persistence has important healthcare economic implications. The primary objective of this study was to identify patient-reported reasons for discontinuation with teriparatide. 


\section{Materials and Methods}

This study was based on questionnaires completed at a subset of sites participating in the direct analysis of nonvertebral fractures in the community experience (DANCE) study [13], a prospective, observational trial designed to examine the efficacy and tolerability of teriparatide as used in clinical practice (ClinicalTrials.gov Identifier: NCT01078805). The multicenter, multispecialty study enrolled patients who were treated with teriparatide and a protocol amendment included questionnaires at baseline (QB), and 2 follow-up questionnaires completed between Month 2 and Month 6 (QF1), and at Month 12 (QF2). The full questionnaires are available in Figures 1, 2, and 3 in Supplementary Material (available online at doi: 10.4061/2011/314970) and were constructed based on the findings from a study by Brod et al. [14] (see below). The QB included items related to the patient's prior experience with self-injection of drugs, perception of the severity of their osteoporosis, relationship with the prescribing physician and his or her staff, and concerns about starting treatment. QF1 and QF2 included items related to initial therapy training and ongoing support, early experience with teriparatide (including problems, adverse events, and concerns), and whether the patient was currently taking teriparatide. Patients who discontinued teriparatide between baseline and Month 12 were asked to choose from among 6 possible reasons for discontinuation: "taken as long as physician prescribed," "did not believe it was beneficial," "too hard to follow all the steps necessary to use Forteo," "problems with injecting," "concerns about treatment outweighed the benefits of treatment," and "cost issues-difficulty paying for it." Discontinuation reported at QF1 and QF2 was defined as "early" and "late," respectively. Patients who did not report discontinuation were considered persistent. DANCE was an observational study and thus all patient care was chosen and conducted at the discretion of the participating study physician according to their clinical judgment and the local standard of medical care. The fulfillment of teriparatide prescriptions was at the discretion of the patient and could have been mail-ordered or at a retail pharmacy. There was a customer care program available for teriparatide patients concurrent with the study (e.g., see QF1, no. 6 and QF2, no. 3). However, patients in DANCE were not required to use the customer program and teriparatide patients could use the customer program regardless of their involvement in DANCE.

2.1. Statistical Analyses. Summary statistics for baseline demographic and medical characteristics were calculated for all patients who had completed QB $(n=1267)$. Ordered categorical responses to the questions were scored numerically as consecutive integers. Some questions with a conditional sequential response structure were collapsed to single ordinal responses. For example, QF1 included "Have you experienced any side effects with the drug, Forteo." Those patients answering "yes" were asked to choose if the side effects were "mild," "moderate," or "severe." The sequence of answers was converted to a single ordinal response: "severe side effects," "moderate side effects," or "mild side effects," and "no side effects." The method resulted in 17 items for QB, 24 items

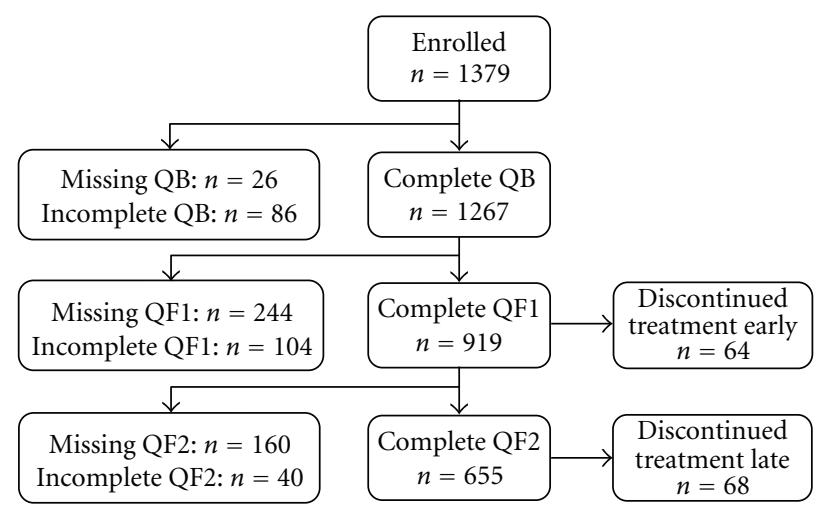

Figure 1: Patient flow chart.

for QF1, and 23 items for QF2. All tests of association were evaluated by the asymptotic Cochran-Armitage trend test. Tests were against the 2 -sided alternative of a positive or negative association at the 0.05 level. Analyses were performed using SAS v9.1.3 for Windows (Cary, NC, USA).

Associations were tested between the following:

(i) survey items in $\mathrm{QB}$ and early treatment discontinuation for those patients who fully completed QB and QF1,

(ii) survey items in QF1 and early treatment discontinuation for those patients who fully completed QB and QF1,

(iii) survey items in QF2 and late treatment discontinuation for those patients who fully completed QB, QF1, and QF2.

\section{Results and Discussion}

Of the 1379 patients who enrolled, 1267 (92\%) completed QB in full (Figure 1). Of these, 919 had complete QB and QF1 and were included in the analysis of early discontinuation. There were 655 patients who also had complete QF2 and were included in the analysis of late discontinuation. There were 404 patients (32\% of 1267) who had one or more missing follow-up survey(s) and 144 patients (11\% of 1267) who had one or more incomplete survey(s).

The characteristics of the cohort are described in Table 1. The patients were mostly white females, but there was notable representation of Hispanic patients. Nearly 1 in 3 had experienced at least one fragility fracture and about 4 out of 5 patients had a history of prior osteoporosis therapy. The mean T-scores for the lumbar spine, femoral neck, and total hip were somewhat higher than the range typically considered osteoporotic ( -2.5 or lower).

Upon initiating teriparatide treatment, the patients had relatively homogeneous attitudes about their disease, which are summarized briefly. Most patients $(n=746,59 \%)$ believed that their osteoporosis was "severe" or "very severe." Nearly all $(n=1217,96 \%)$ believed that it was "very" or "extremely important" to treat their osteoporosis. Many patients $(n=1064,84 \%)$ believed teriparatide would be 
TABLe 1: Demographics and baseline characteristics.

\begin{tabular}{|c|c|c|}
\hline Variable & $N$ & Value \\
\hline Age in years, mean (SD) & 1267 & $66.9(11.4)$ \\
\hline Female gender, $n(\%)$ & 1267 & $1151(90.8 \%)$ \\
\hline Race, $n(\%)$ & 1267 & \\
\hline White & & $999(78.9 \%)$ \\
\hline African American & & $18(1.4 \%)$ \\
\hline Hispanic & & $230(18.2 \%)$ \\
\hline Other & & $20(1.6 \%)$ \\
\hline Education, $n(\%)$ & 999 & \\
\hline$<$ High school & & $52(5.2 \%)$ \\
\hline High school & & $437(43.7 \%)$ \\
\hline College & & $414(41.4 \%)$ \\
\hline Graduate school & & $96(9.6 \%)$ \\
\hline $\begin{array}{l}\text { History of } \geq 1 \text { fragility } \\
\text { fracture, } n(\%)\end{array}$ & 1226 & $388(31.7 \%)$ \\
\hline $\begin{array}{l}\text { History of prior osteoporosis } \\
\text { therapy, } n(\%)\end{array}$ & 1254 & $1036(82.6 \%)$ \\
\hline $\begin{array}{l}\text { Family history of } \\
\text { osteoporosis, } n(\%)\end{array}$ & 1176 & $481(40.9 \%)$ \\
\hline $\begin{array}{l}\text { Family history of hip } \\
\text { fracture, } n(\%)\end{array}$ & 1177 & $232(19.7 \%)$ \\
\hline $\begin{array}{l}\text { Lumbar spine } \mathrm{T} \text {-score, mean } \\
\text { (SD) }\end{array}$ & 1012 & $-2.34(1.44)$ \\
\hline $\begin{array}{l}\text { Femoral neck T-score, mean } \\
\text { (SD) }\end{array}$ & 976 & $-2.30(0.97)$ \\
\hline Total hip T-score, mean (SD) & 777 & $-1.97(1.00)$ \\
\hline $\begin{array}{l}\geq 1 \text { active medical condition, } \\
n(\%)\end{array}$ & 1255 & $1066(84.9 \%)$ \\
\hline Smoking, $n(\%)$ & 1191 & $173(14.5 \%)$ \\
\hline Alcohol, $n(\%)$ & 1172 & $289(24.7 \%)$ \\
\hline Caffeine, $n(\%)$ & 1077 & $912(84.7 \%)$ \\
\hline
\end{tabular}

"very" or "extremely effective" at reducing the risk of future fractures. Some patients $(n=374,30 \%)$ were "very" or "extremely concerned" about their ability to pay for treatment. While only a few patients had experience using self-injectable medications $(n=252,20 \%)$, most $(n=789$, $62 \%)$ were "very" or "extremely confident" in their ability to inject themselves daily as instructed. Few patients thought they would need help with the injections $(n=161,13 \%)$. Approximately 1 in 4 patients experienced side effects $(n=$ $234,25 \%)$ with about half of these $(n=120)$ reporting that the effects were "moderate" or "severe." When QF2 was administered, 15\% (96 of 655) of the remaining patients reported having experienced side effects.

Early discontinuation of teriparatide was reported by 64 (7\% of 919) patients and an additional 68 (10\% of 655$)$ patients reported late discontinuation. For both early and late discontinuation, the most commonly selected reasons were financial difficulties and concerns about treatment
TABLE 2: Reasons given for discontinuation of teriparatide therapy for those patients who reported early or late discontinuation.

\begin{tabular}{|c|c|c|}
\hline Time of discontinuation & $\begin{array}{c}\text { early } \\
N(\%)\end{array}$ & $\begin{array}{l}\text { late } \\
n(\%)\end{array}$ \\
\hline $\begin{array}{l}\text { Concerns about treatment } \\
\text { outweighed the benefits }\end{array}$ & $27(42.2)$ & $26(38.2)$ \\
\hline Cost issues_difficulty paying for it & $19(29.7)$ & $28(41.2)$ \\
\hline $\begin{array}{l}\text { Taken as long as physician } \\
\text { prescribed }\end{array}$ & $11(17.2)$ & $10(14.7)$ \\
\hline Problems with injecting & $8(12.5)$ & $3(4.4)$ \\
\hline Did not believe it was beneficial & $4(6.3)$ & $7(10.3)$ \\
\hline $\begin{array}{l}\text { Too hard to follow all the steps } \\
\text { necessary to use Forteo }\end{array}$ & $3(4.7)$ & $0(0.0)$ \\
\hline Reason unspecified & $2(3.1)$ & $2(2.9)$ \\
\hline
\end{tabular}

${ }^{a}$ Note that some patients reported more than one reason. A total of 64 patients discontinued early and 68 discontinued late.

outweighing the benefits (Table 2). No items in QB were significantly associated with early discontinuation. Associations between items on survey QF1 and early discontinuation are summarized in Figure 2. The discontinuation rate increased with the reported severity of side effects $(P<.001)$. For the 685 patients who reported no side effects, fewer than $5 \%$ discontinued. In contrast, $56 \%$ of the 27 patients reporting severe side effects discontinued. Patients who were concerned that they were not taking the medication properly were more likely to have discontinued early than if they had little or no concerns about proper administration $(P=$ .01 ). Five different items relating to difficulties with the injection device were associated with early discontinuation (all $P<.001$ ); an example is shown in Figure 2. There were also associations between early discontinuation and the perception that the prescribing physician had a low level of knowledge about teriparatide $(P=.001)$, low enthusiasm about treatment $(P=.01)$, or a low level of confidence in the treatment (shown in Figure 2, $P<.001$ ).

The late discontinuation rate was highest for patients who "never" experienced pain at the injection site (Figure 3, $P=.002)$. Most patients had not used the patient assistance telephone line. However, 2 of the 5 patients who did not think it was helpful discontinued. None of the 49 patients who had called and found the assistance "very" or "extremely" helpful had discontinued. Problems paying for medication was also significantly associated with late discontinuation $(P<.001)$. Patients who thought it was "not at all" or "only a little" important to continue treatment were more likely to discontinue $(P<.001)$. Similar to early discontinuation, patient-perceived physician knowledge $(P=.01)$ and side effects $(P<.001)$ remained important factors with late discontinuation.

The characteristics of patients initiating teriparatide in this prospective observational study were consistent with previous reports from administrative claims databases $[15,16]$. As was seen in this study, most patients were female, 


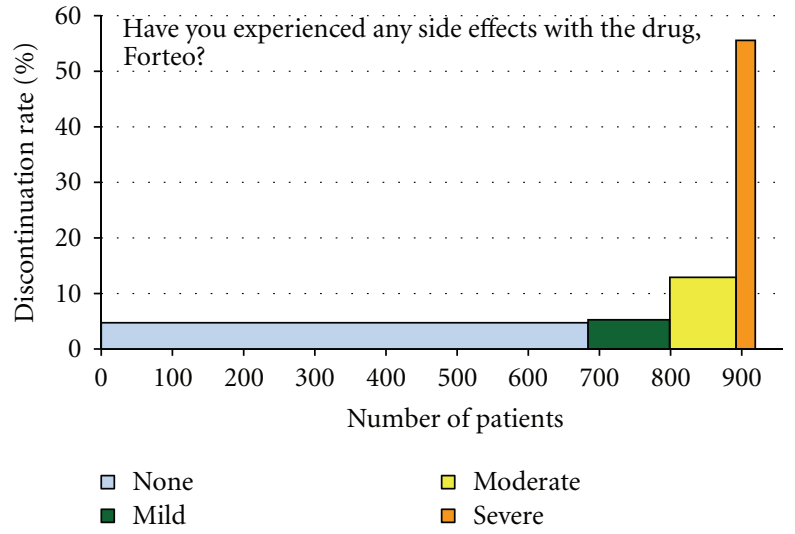

(a)

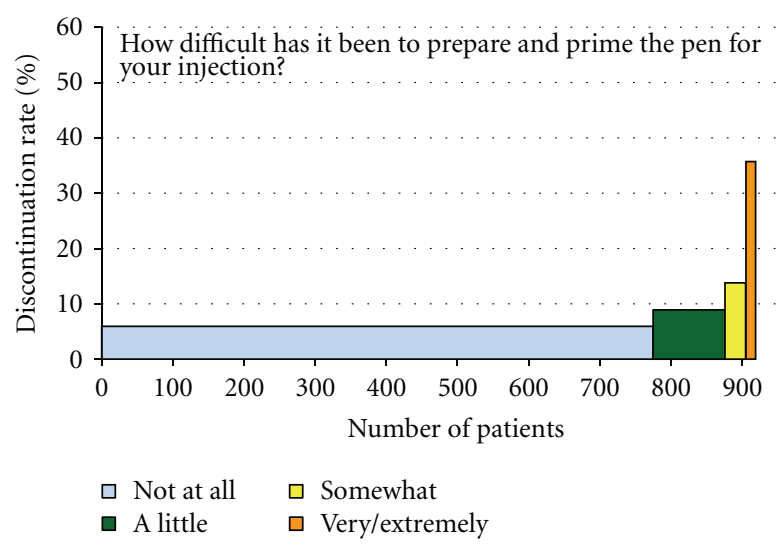

(c)

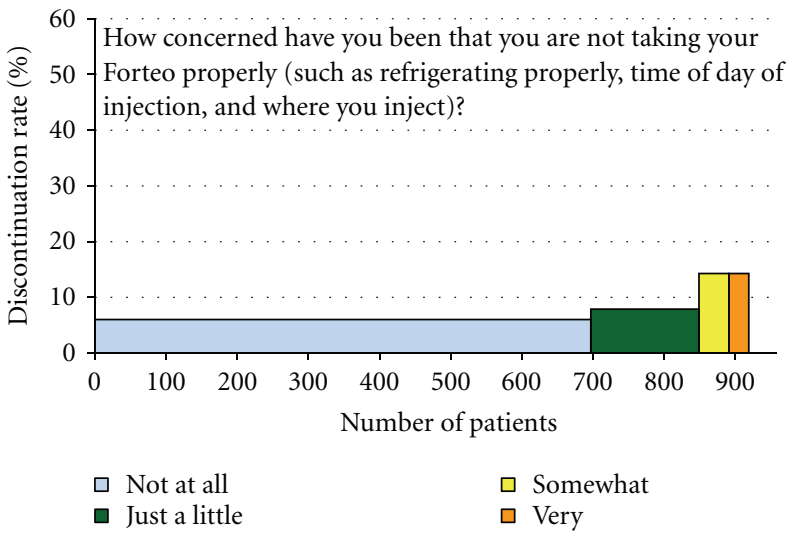

(b)

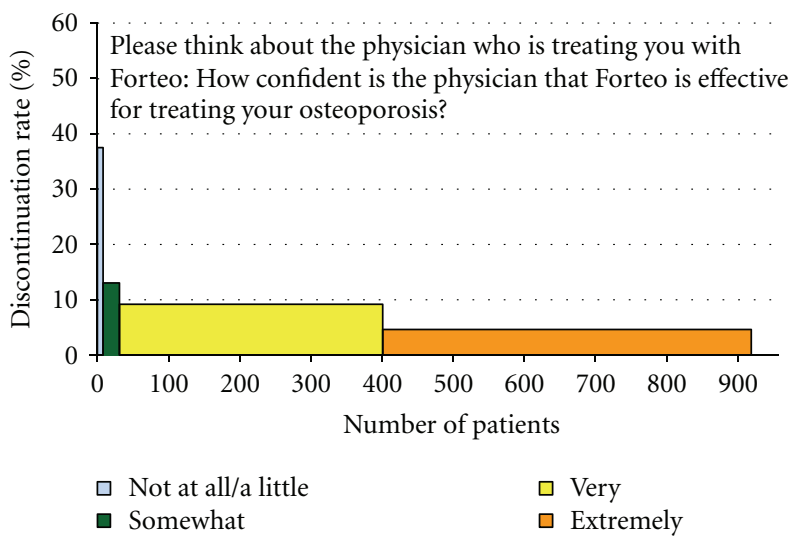

(d)

FIGURE 2: Responses to QF1 significantly associated with early discontinuation (Cochran-Armitage trend test). Additional significant associations, which had trends similar to the questions shown, included: How difficult has it been to: set the dose? inject yourself? clean and store the pen? Other? Overall, how difficult has it been to use Forteo as prescribed? Please think about the physician who is treating you with Forteo: How enthusiastic is the physician about treatment with Forteo? How knowledgeable is the physician about treatment with Forteo?

older than age 65 , and had previously used other medications such as antiresorptives to treat their osteoporosis. Patients commonly had a history of osteoporotic fracture. A strength of the current study is that results from bone mineral density measurements were available. The baseline mean T-score was not in the range (i.e., -2.5 or lower) typically considered osteoporotic [17]. One possible explanation is that the investigators in the DANCE study may be less focused on only bone mineral density and have taken into consideration additional risk factors, such as age and previous fracture, that have been shown to be strong predictors of future fracture [18]. Side effects were significantly associated with both early and late discontinuation. In other studies, discontinuation due to adverse events was $4 \%$ in the UK [19], 8\% in France [20], 6\% in Europe [21], and 6\% in an international clinical trial [22].

The 3 questionnaires administered over the first 12 months of treatment were used to identify a number of patient-reported factors associated with discontinuation. Difficulty paying for treatment and concerns outweighing the benefits were most commonly selected by the patients as reasons for discontinuation. When the remaining patient responses were correlated with discontinuation, side effects and financial issues were significantly associated, consistent with the patient-selected reasons. Additional factors associated with early discontinuation included concern about improper usage, difficulty with the self-injection, and the patient's perception of the prescriber. A patient not perceiving the importance of continuing treatment was associated with late discontinuation.

Unexpectedly, pain at the injection site was associated with persistence rather than discontinuation. One possible explanation is that if patients misinterpreted the intent of the question, those who discontinued could have reported that they no longer experienced pain, because they were no longer injecting teriparatide. On the other hand, of the 14 patients who reported pain at the injection site "most" or "all" of the time, only 1 of those discontinued treatment.

Also of interest is that even though "problems with injecting" was only the fourth most common prespecified reason provided for discontinuing treatment, significant trends were observed with several other questionnaire items 


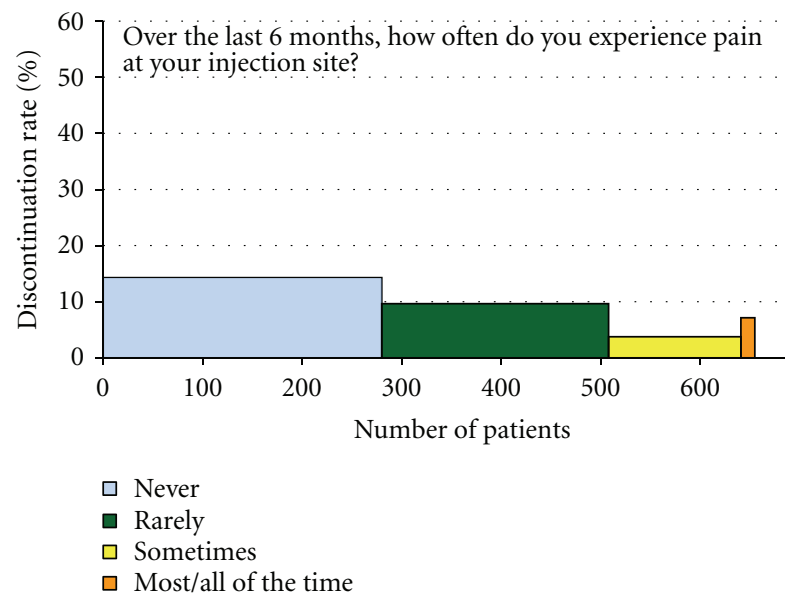

(a)

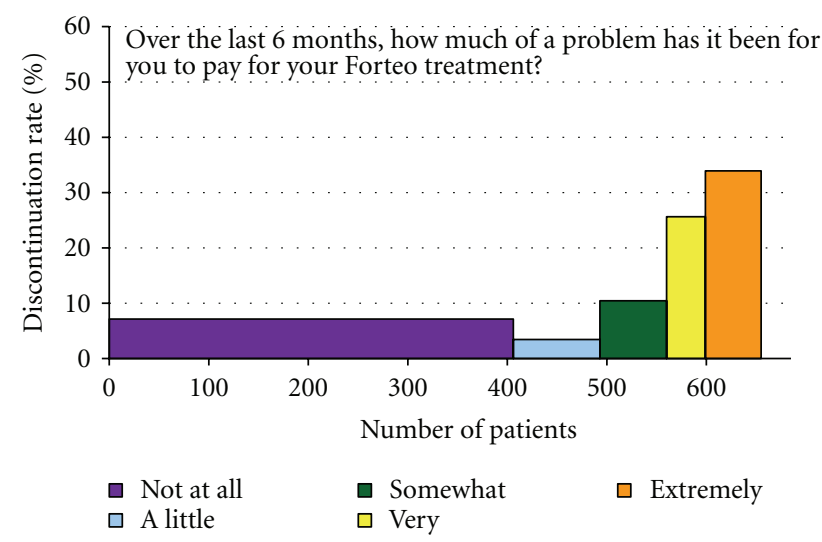

(c)

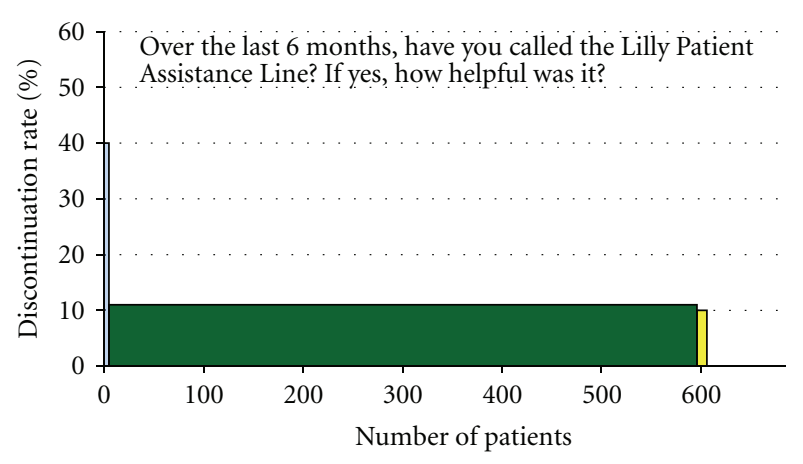

$\square$ Not helpful (5 patients, 2 discontinued)

- Did not call (591 patients, 65 discontinued)

口 A little/somewhat helpful (10 patients, 1 discontinued)

․ Very/extremely helpful (49 patients, 0 discontinued)

(b)

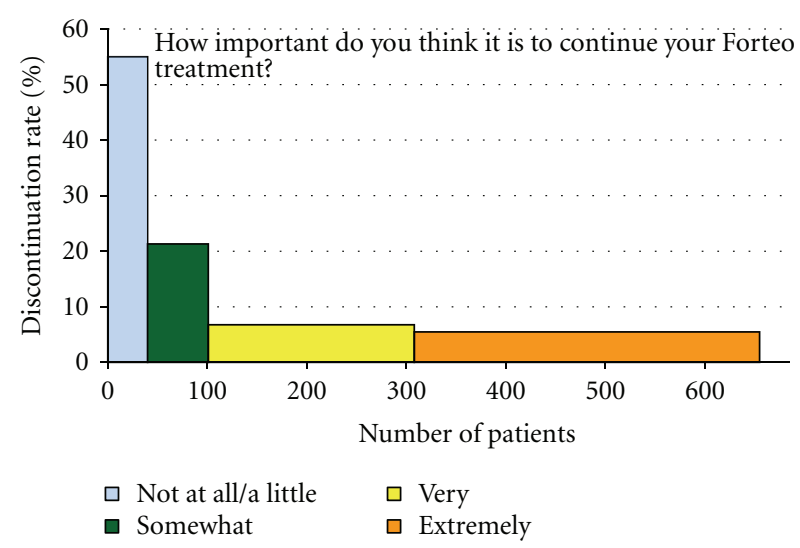

(d)

FIgURE 3: Responses to QF2 significantly associated with late discontinuation (Cochran-Armitage trend test). Additional significant associations had trends similar to the questions shown and included: Over the last 6 months, have you experienced any side effects with the drug, Forteo? If yes, were they mild, moderate, or severe? Please think about the physician who is treating you with Forteo: How knowledgeable is the physician about treatment with Forteo?

focused on injection difficulties. Perhaps difficulties with the injection device is typically not sufficient as a primary reason for discontinuation, but it was a contributing factor when combined with other issues. such as cost or the benefit-risk balance. Although approved for marketing after the time of this study, a newer device has been developed, evaluated in a clinical trial (ClinicalTrials.gov identifier NCT00577863) and is now the standard device patients use to inject teriparatide.

The factors associated with persistence highlight the need for better strategies to optimize teriparatide use. In other studies of injectable treatments, patients' self-perceived efficacy, attitudes toward the disease and the treatment, sense of hope, perception of the physician as supportive, as well as the interaction between the patient and the healthcare team strongly influenced adherence $[23,24]$. In a qualitative study, Brod et al. developed a conceptual model of persistence and adherence with injectable drugs based on semistructured interviews of patients and physicians who received/prescribed teriparatide [14]. The final model reflected that adherence and persistence were continuing processes that were influenced by both patient and physician factors and that the process began before initiation of therapy. As in this study, the physician's level of enthusiasm for the treatment, perceived knowledge about treatment, resources devoted to training, and continued support around treatment were important factors. Also, as in this study, patient's perceptions that their illness was severe, that they were at risk for fracture, and that treatment was likely to be effective, financial concerns were important factors in treatment initiation, with initial experience and side effects being important factors for short-term persistence. The authors also identified perceived efficacy playing a role in longer-term persistence. Improved communication between patient and physician, and, more specifically, providing feedback based on biomarkers and highlighting the benefits of treatment rather than instilling fear about consequences of nonadherence were also stressed in a review of optimizing efficacy with bisphosphonates treatment [25]. 
The most important limitation of this study is the lack of data on patients who were lost to followup. It was unknown whether these patients were still on therapy, and if not, what their reasons were for discontinuation. Second, it is uncertain whether the DANCE population was representative of prescribers and patients across the United States. For example, many of the study investigators were considered national experts and might have more experience and expertise with initiating and continuing patients on teriparatide than typical prescribers. The results presented here might not apply to different patient populations. Third, the length of followup included in this report was limited to 1 year, so longer-term issues with persistence might not be addressed. Finally, the data were collected from patient self-reports using surveys with only a limited number of prespecified possible responses, which might not be a comprehensive or accurate record of the patient's true experience.

\section{Conclusions}

We observed a notably high level of persistence in this prospective observational study, which raises the possibility that the DANCE patients might share certain characteristics or level of care that led to less discontinuation. Lower levels of persistence might be expected on a national level, where the population consists of a more diverse group of patients and health care providers. The use of training or support programs within DANCE might or might not be greater than the general population, so we cannot confidently extrapolate these results.

If nurses and other staff members are the individuals performing the training, they could be key partners to monitor and improve persistence. It should also be noted that although the study was designed to be observational, the questionnaires themselves could have had an interventional affect to improve persistence. Further studies of persistence with teriparatide might help clarify the preliminary findings reported here. For example, because Medicare Part D has led to shifts in US patient populations and payment arrangements [26], analyses with more recent data are of substantial interest. The 2010 healthcare reform in the United States could also change the treatment patterns again. Finally, as teriparatide becomes commercially available in new countries throughout the world, it will be important to consider whether the factors associated with discontinuation in the United States apply to other geographies.

\section{Conflict of Interests}

G. Pohl, K. D. Krohn, Y. Chen, and E. S. Meadows are full-time employees of and hold stock in Lilly Research Laboratories. D. T. Gold has served as a consultant for Amgen, Procter \& Gamble, GlaxoSmithKline, F. Hoffman-La Roche Ltd., sanofi-aventis, Roche Diagnostics, Eli Lilly, and Novartis. Additionally, she has received travel grants, speaking or writing fees, or other honoraria, and has served as a member of an advisory board for Amgen, Procter \& Gamble, GlaxoSmithKline, F. Hoffman-La Roche Ltd., sanofi-aventis, Roche Diagnostics, Novartis, and Eli Lilly. D. L. Weinstein has been a consultant for Eli Lilly and served as an advisor and/or speaker for Amgen, Eli Lilly, GlaxoSmithKline, Novartis, and Roche Laboratories.

\section{Acknowledgments}

The authors thank Drs. Matthew D. Rousculp and Meryl Brod for their work in the development of the questionnaires and the initial conception of the DANCE addendum. Dr. Rachel Wagman provided oversight for the DANCE study. Asad Rana provided programming in support of the statistical analyses, and Dr. Tamara Ball provided writing and editorial support. Dr. Ball is a scientific writer employed full-time by i3 Statprobe, a division of Ingenix, which is a subsidiary of United Health Group. Eli Lilly contracted with i3 Statprobe for technical assistance in the writing of this manuscript. The authors are indebted to all the patients and investigators who participated in the study. The DANCE study was funded by Eli Lilly and Company.

\section{References}

[1] National Osteoporosis Foundation, Clinician's Guide to the Prevention and Treatement of Osteoporosis, National Osteoporosis Foundation, Washington, DC, USA, 2008.

[2] J. Y. Reginster, V. Rabenda, and A. Neuprez, "Adherence, patient preference and dosing frequency: understanding the relationship," Bone, vol. 38, no. 4, pp. S2-S6, 2006.

[3] J. Y. Reginster, "Adherence and persistence: impact on outcomes and health care resources," Bone, vol. 38, no. 2, pp. S18S21, 2006.

[4] D. Weycker, D. Macarios, J. Edelsberg, and G. Oster, "Compliance with drug therapy for postmenopausal osteoporosis," Osteoporosis International, vol. 17, no. 11, pp. 1645-1652, 2006.

[5] D. Weycker, D. Macarios, J. Edelsberg, and G. Oster, "Compliance with osteoporosis drug therapy and risk of fracture," Osteoporosis International, vol. 18, no. 3, pp. 271-277, 2007.

[6] J. S. McCombs, P. Thiebaud, C. McLaughlin-Miley, and J. Shi, "Compliance with drug therapies for the treatment and prevention of osteoporosis," Maturitas, vol. 48, no. 3, pp. 271287, 2004.

[7] T. W. Downey, S. H. Foltz, S. J. Boccuzzi, M. A. Omar, and K. H. Kahler, "Adherence and persistence associated with the pharmacologic treatment of osteoporosis in a managed care setting," Southern Medical Journal, vol. 99, no. 6, pp. 570-575, 2006.

[8] J. A. Cramer, D. T. Gold, S. L. Silverman, and E. M. Lewiecki, "A systematic review of persistence and compliance with bisphosphonates for osteoporosis," Osteoporosis International, vol. 18, no. 8, pp. 1023-1031, 2007.

[9] A. N. A. Tosteson, M. R. Grove, C. S. Hammond et al., "Early discontinuation of treatment for osteoporosis," American Journal of Medicine, vol. 115, no. 3, pp. 209-216, 2003.

[10] A. Sebaldt, L. G. Shane, B. Pham, R. Cook, L. Thabane, and A. Petrie, "Long-term effectiveness outcomes of non-compliance and non-persistence with daily regimen bisphoshonate therapy in patients with osteoporosis treated in tertiary specialist care," Osteoporosis International, vol. 15, p. S107, 2004, Abstract P391SA. 
[11] R. Eastell, P. Garnero, L. Vrigens, L. Van de Langerijt, H. A. P. Pols, and J. D. Ringe, "Influence of patient compliance with risedronate therapy on bone turnover marker and bone mineral density response: the IMPACT study," Calcified Tissue International, vol. 72, p. 408, 2003, Abstract P297.

[12] Forteo [package insert], Eli Lilly and Company, Indianapolis, Ind, USA, 2010.

[13] P. D. Miller, S. L. Silverman, D. T. Gold, K. A. Taylor, P. Chen, and R. B. Wagman, "Rationale, objectives and design of the Direct Analysis of Nonvertebral Fracture in the Community Experience (DANCE) Study," Osteoporosis International, vol. 17, no. 1, pp. 85-90, 2006.

[14] M. Brod, M. Rousculp, and A. Cameron, "Understanding compliance issues for daily self-injectable treatment in ambulatory care settings," Patient Prefer Adherence, vol. 2, pp. 129-136, 2008.

[15] S. A. Foster, K. A. Foley, E. S. Meadows et al., "Characteristics of patients initiating teriparatide for the treatment of osteoporosis," Osteoporosis International, vol. 19, no. 3, pp. 373-377, 2008.

[16] E. S. Meadows, M. Rousculp, A. C. Sasser et al., "Actual versus predicted first-year utilization patterns of teriparatide in patients with employer-sponsored health insurance," Current Medical Research and Opinion, vol. 23, no. 12, pp. 3215-3222, 2007.

[17] National Osteoporosis Foundation, America's Bone Health: The State of Osteoporosis and Low Bone Mass in Our Nation, National Osteoporosis Foundation, Washington, DC, USA, 2010.

[18] J. A. Kanis, A. Oden, O. Johnell et al., "The use of clinical risk factors enhances the performance of BMD in the prediction of hip and osteoporotic fractures in men and women," Osteoporosis International, vol. 18, no. 8, pp. 1033-1046, 2007.

[19] N. K. Arden, S. Earl, D. J. Fisher, C. Cooper, S. Carruthers, and M. Goater, "Persistence with teriparatide in patients with osteoporosis: the UK experience," Osteoporosis International, vol. 17, no. 11, pp. 1626-1629, 2006.

[20] K. Briot, P. Ravaud, P. Dargent-Molina, M. Zylberman, S. LiuLeage, and C. Roux, "Persistence with teriparatide in postmenopausal osteoporosis; Impact of a patient education and follow-up program: The French experience," Osteoporosis International, vol. 20, no. 4, pp. 625-630, 2009.

[21] B. L. Langdahl, G. Rajzbaum, F. Jakob et al., "Reduction in fracture rate and back pain and increased quality of life in postmenopausal women treated with teriparatide: 18-month data from the European Forsteo Observational Study (EFOS)," Calcified Tissue International, vol. 85, no. 6, pp. 484-493, 2009.

[22] R. M. Neer, C. D. Arnaud, J. R. Zanchetta et al., "Effect of parathyroid hormone (1-34) on fractures and bone mineral density in postmenopausal women with osteoporosis," New England Journal of Medicine, vol. 344, no. 19, pp. 1434-1441, 2001.

[23] C. Fraser, O. Hadjimichael, and T. Vollmer, "Predictors of adherence to Copaxone therapy in individuals with relapsingremitting multiple sclerosis," The Journal of Neuroscience Nursing, vol. 33, no. 5, pp. 231-239, 2001.

[24] S. Schwartzman and G. J. Morgan Jr., "Does route of administration affect the outcome of TNF antagonist therapy?" Arthritis Research and Therapy, vol. 6, no. 2, pp. S19-S23, 2004.
[25] O. Bock and D. Felsenberg, "Bisphosphonates in the management of postmenopausal osteoporosis-optimizing efficacy in clinical practice," Clinical Interventions in Aging, vol. 3, no. 2, pp. 279-297, 2008.

[26] W. Yin, A. Basu, J. X. Zhang, A. Rabbani, D. O. Meltzer, and G. C. Alexander, "The effect of the medicare part D prescription benefit on drug utilization and expenditures," Annals of Internal Medicine, vol. 148, no. 3, pp. 169-177, 2008. 


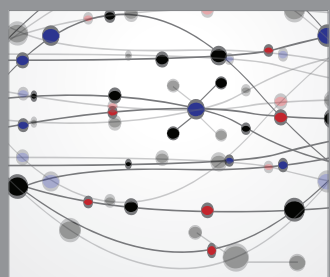

The Scientific World Journal
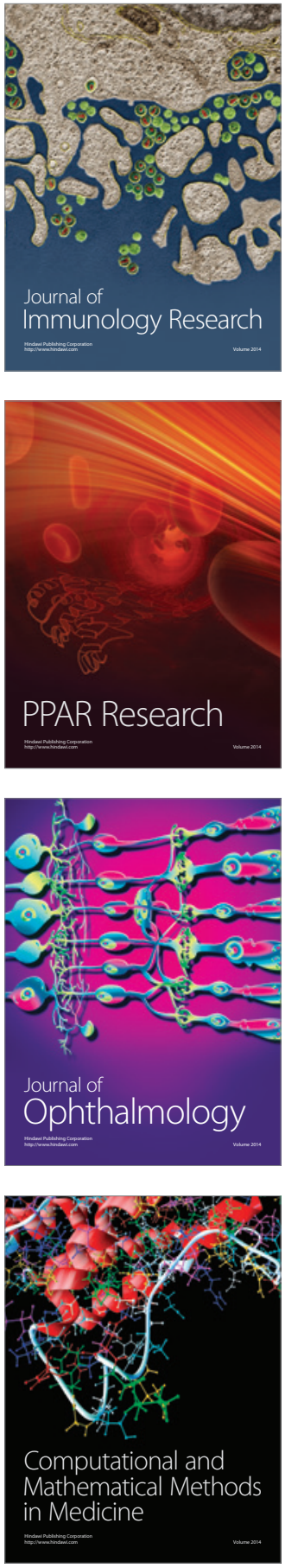

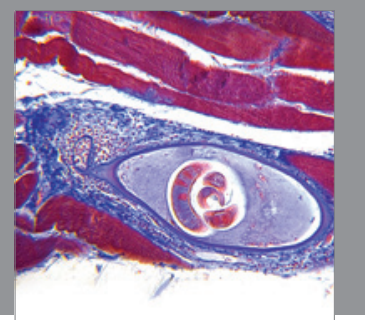

Gastroenterology

Research and Practice
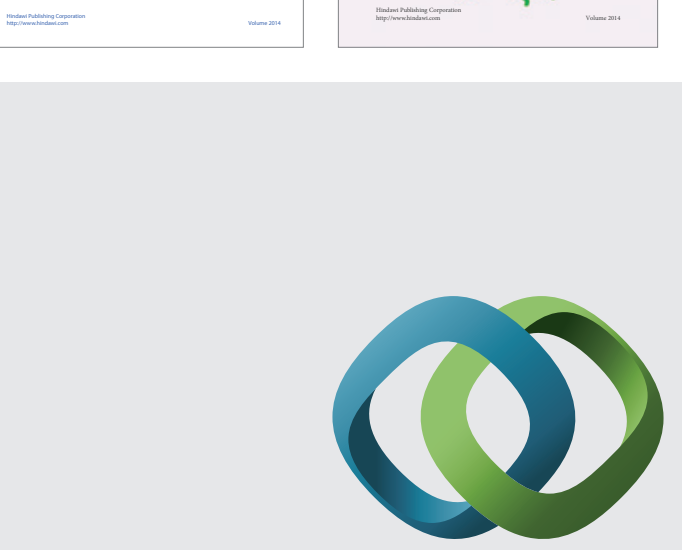

\section{Hindawi}

Submit your manuscripts at

http://www.hindawi.com
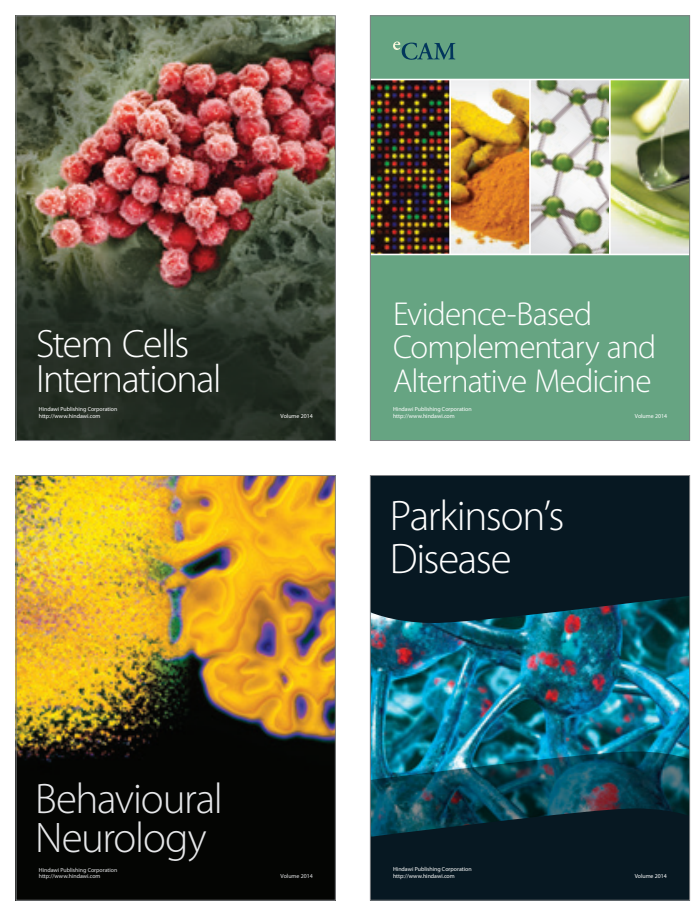

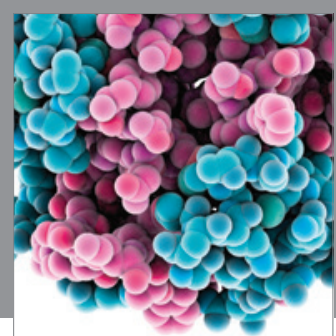

Journal of
Diabetes Research

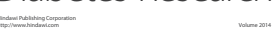

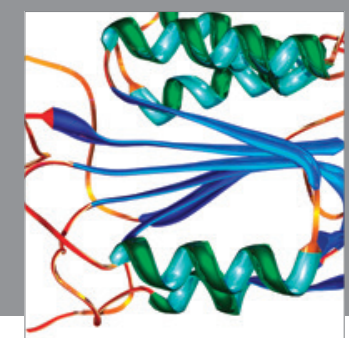

Disease Markers
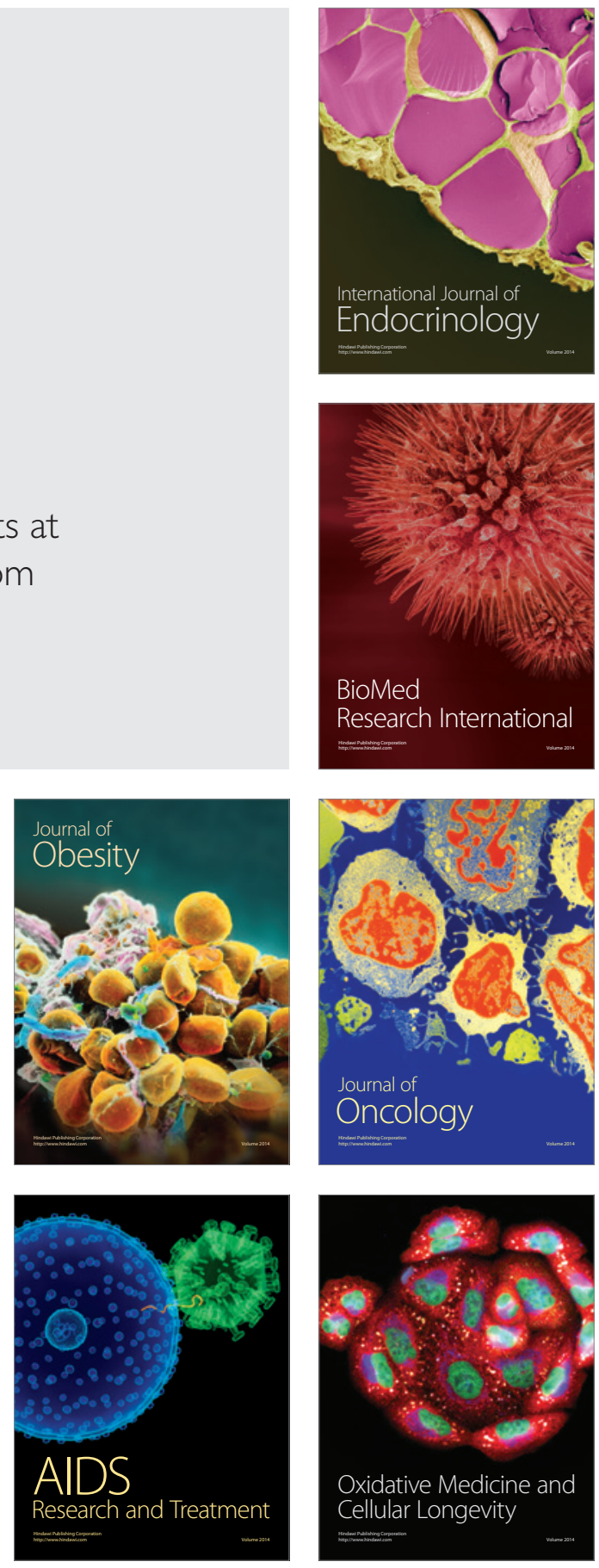